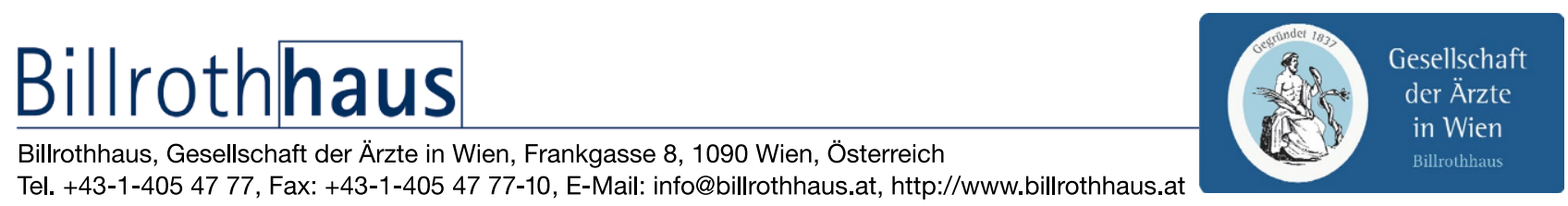

\section{Vorschau auf das Wintersemester 2018/19:}

\author{
Medizin \& Geschichte: Medical \\ History Tour \\ Termin: 13.09.2018, 15.00 Uhr \\ Tagung: VSCR - Science \\ Summit: Volksgesundheit \\ - Gefäßerkrankungen \\ Termin: 14.09.2018, 9.00 Uhr
}

Medizin \& Geschichte: Open House Wien 2018

Termin: 16.09.2018, 10.00-17.00 Uhr

meet \& tweet: Update Dermatitis Termin: 20.09.2018, 18.00 Uhr

Medizin interaktiv: Biomedical Research Workshop

Termin: 24.09.2018, 16.00 Uhr

Medizin \& Geschichte: Tag des

Denkmals: Schätze teilen

Termin: 30.09.2018, 10.00 Uhr

Programmänderungen vorbehalten!

Alle Detailprogramme können Sie unter www. billrothhaus.at oder mit Einscannen des QR-Codes aufrufen:

\section{Werden Sie Mitglied!}

Die Gesellschaft der Ärzte in Wien wurde im Jahr 1837 gegründet und zählt zu den bedeutendsten medizinischen Vereinen. Schon Freud, Landsteiner und Rokitansky waren Teil dieser Gesellschaft. Damals wie heute stehen die Vermittlung und Erweiterung des medizinischen Fachwissens im Vordergrund. Werden auch Sie Teil dieser bedeutsamen Gesellschaft!

Ihre Vorteile im Überblick:

- Zugriff auf mehr als 3000 E-Journals im Volltext sowie auf 100.000 Bände an Printzeitschriften

- Rund 50 medizinisch-wissenschaftliche Eigenveranstaltungen pro Jahr

- Erwerb von rund 100 DFP-Punkten pro Jahr durch die Teilnahme an unseren Veranstaltungen

- Videoplattform Billrothhaus.TV mit über 500 Fortbildungsvideos unserer Eigenveranstaltungen

- Zugriff auf DynaMed Plus

- Postalische Zustellung des Semesterprogrammes

- Zusendung von Newsletter (monatlich) und Veranstaltungs-Reminder

- Vergünstigte Tarife für Medizinstudierende und pensionierte ÄrztInnen

Mit Ihrem Beitrag unterstützen Sie außerdem den Erhalt des denkmalgeschützten Billrothhauses!
Registrieren Sie sich online unter www. billrothhaus.at oder kontaktieren Sie uns persönlich (Tel.: +431405 47 77, E-Mail: info@billrothhaus.at). Wir freuen uns auf Sie!

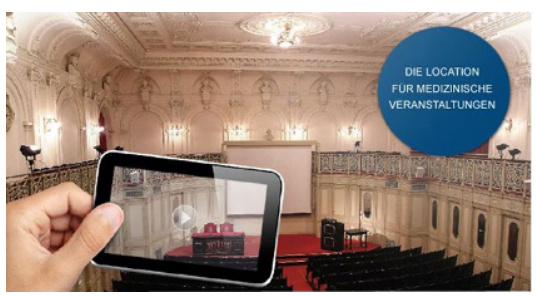

Sie finden uns auch auf Facebook!

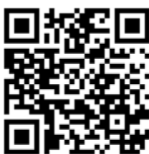

Besuchen Sie uns auf der Facebook Seite der Gesellschaft der Ärzte in Wien!

Was Sie erwartet:

- Informationen rund um die Gesellschaft

- spannende Veranstaltungstipps

- sowie Videos und Online-Fortbildungen auf Billrothhaus.TV

Ihre Meinung ist uns wichtig. Wir freuen uns über Ihre aktive Beteiligung und Ihre Kommentare! 